\title{
On solutions of PDEs by using algebras
}

ELIFALET LÓPEZ-GONZÁLEZ ${ }^{1}$ and Elifalet López-González ${ }^{2,3}$

\author{
${ }^{1}$ Affiliation not available \\ ${ }^{2}$ DM de la UACJ en Cuauhtémoc, Universidad Autónoma de Ciudad Juárez, Carretera \\ Cuauhtémoc-Anáhuac \\ ${ }^{3} \mathrm{Cd}$. Cuauhtémoc
}

October 14, 2021

\section{Hosted file}

solpdedosdving.pdf available at https://authorea.com/users/405599/articles/541619-onsolutions-of-pdes-by-using-algebras 